\title{
Estado nutricional e teste do hidrogênio no ar expirado com lactose e lactulose em crianças indígenas terenas
}

\author{
Nutritional status and breath hydrogen test with lactose and lactulose \\ in Terena Indian children
}

\author{
Gildney Maria dos Santos Alves' ${ }^{1}$, Mauro Batista de Morais ${ }^{2}$, Ulysses Fagundes-Neto ${ }^{3}$
}

\begin{abstract}
Resumo
Objetivo: avaliar o estado nutricional, a absorção e a tolerância à lactose e a ocorrência de sobrecrescimento bacteriano no intestino delgado.

Métodos: estudo transversal envolvendo todas as 264 crianças índias terenas, menores de 10 anos, das aldeias Limão Verde e Córrego Seco, em Aquidauana (MS). O estado nutricional foi avaliado pelo peso e pela estatura, relacionados com a referência do NCHS. Após a ingestão de 18 gramas de lactose, foi avaliada sua absorção, pelo teste do hidrogênio no ar expirado, e a tolerância de acordo com o aparecimento de manifestações clínicas. Sobrecrescimento bacteriano no intestino delgado foi avaliado com o teste do hidrogênio no ar expirado após a administração de lactulose (5g).

Resultados: a mediana dos escores $\mathrm{Z}$ do peso-idade, pesoestatura e estatura-idade para as crianças com idade inferior a 12 meses $(n=34)$ foram, respectivamente: $-0,66,+0,60$ e $-0,85$. Entre 1 e $5 \operatorname{anos}(n=111)$ foram, respectivamente: $-0,50,+0,28$ e $-1,17$. Entre os 5 e 10 anos ( $n=119)$, estes valores foram, respectivamente: $-0,09$, $+0,50$ e -0,60. Após os 4 anos $(n=197)$, absorção deficiente e má absorção de lactose foi observada em 89,3\% das 197 crianças avaliadas. Intolerância à lactose foi observada em 37,1\% destas 197 crianças. Sobrecrescimento bacteriano no intestino delgado foi caracterizado em $11,5 \%$ das crianças índias terenas $(n=252)$.

Conclusões: a prevalência de desnutrição atual foi baixa, mas a mediana de estatura para idade foi inferior à referência do NCHS. Prevalência de deficiência ontogenética de lactase é elevada. Sobrecrescimento bacteriano sugere a existência de enteropatia ambiental assintomática nas crianças índias terenas.
\end{abstract}

J Pediatr(Rio J) 2002; 78(2): 113-9: estado nutricional, lactose, lactulose, testes respiratórios, índios sul-americanos, sobrescimento bacteriano no intestino delgado.

1. Professora Adjunta - Doutora do Departamento de Pediatria da Universidade Federal do Mato Grosso do Sul.

2. Professor Adjunto - Livre Docente e Chefe da Disc. de Gastroenterologia Pediátrica da Univ. Federal de São Paulo - Escola Paulista de Medicina.

3. Professor Titular da Disciplina de Gastroenterologia Pediátrica e Chefe do Dep. de Pediatria da Universidade Federal de São Paulo - Escola Paulista de Medicina.

Artigo submetido em 27.06.01, aceito em 04.10.01.

\begin{abstract}
Objective: to evaluate the nutritional status, absorption and tolerance of lactose and the occurrence of small-bowel bacterial overgrowth.

Methods: a cross-sectional study including all 264 Terena Indian children younger than 10 years from two tribes (Limão Verde and Córrego Seco) in Mato Grosso do Sul. The nutritional status was assessed based upon weight and height, using NCHS data as reference. The breath hydrogen test after an oral lactose (18g) administration was used for evaluation of lactose absorption and tolerance. The occurrence of bacterial overgrowth was evaluated using the breath hydrogen test after the administration of lactulose $(5 \mathrm{~g})$.

Results: the median $\mathrm{z}$ scores of weight-for-age, weight-forheight and height-for-age were, respectively, in infants under 1 year $(n=34):-0.66,+0.60$ and -0.85 . Between 1 and 5 years $(n=111)$, the values were: $-0.50,+0.28$ and -1.17 . Between 5 and 10 years $(\mathrm{n}=119)$, these anthropometric values were, respectively: -0.09 , +0.50 and -0.60 . Deficient lactose absorption or malabsorption was verified only after the fourth year of age in $89.3 \%$ of the 197 evaluated children. Lactose intolerance was found in $37.1 \%$ of them. Small-bowel overgrowth was detected in $11.5 \%$ of the Terena Indian children $(\mathrm{n}=252)$.
\end{abstract}

Conclusions: the prevalence of recent malnutrition was low, but the median height-for-age was lower than the NCHS reference. The prevalence of ontogenetic lactase deficiency was high. Bacterial overgrowth may be considered as evidence of the occurrence of nonsymptomatic environmental enteropathy in Terena Indian children.

J Pediatr (Rio J) 2002; 78 (2): 113-9: nutritional status, lactose, lactulose, breath test, South American Indians, small intestine bacterial overgrowth.

\section{Introdução}

A condição de saúde de um determinado grupo populacional depende da expressão das suas características genéticas interagindo com diversos fatores ambientais. Na população infantil, o estado nutricional e o crescimento são classicamente considerados como um dos mais importantes indicadores da sua condição de saúde ${ }^{1}$. Em grupos popula- 
cionais específicos, esses pontos se revestem de um interesse especial, por permitir que sejam feitas comparações entre grupos com diferentes estilos de vida. Isso se aplica aos grupos de indígenas brasileiros, que mais intensamente, nos últimos cinqüenta anos, participam de um processo de modificação social em consequiência do contato e do intercâmbio com a sociedade brasileira não-indígena. No que se refere à condição nutricional da população indígena infantil do Brasil, existem algumas publicações relativas aos índios Caiapós $^{2}$, índios do Alto Xingu ${ }^{3-5}$, da região Amazônica ${ }^{6}$ e xavantes do Mato Grosso ${ }^{7}$.

É do conhecimento geral que os hábitos alimentares desempenham papel de grande relevância na condição nutricional de uma comunidade. Por sua vez, a deficiência ontogenética de lactase pode influenciar no estabelecimento dos hábitos alimentares dos mais variados grupos étnicos existentes no universo. Na população brasileira, foi caracterizada elevada prevalência de deficiência ontogenética de lactase, utilizando a técnica da curva glicêmica após sobrecarga de lactose em adultos jovens ${ }^{8}$, em escolares de um grande centro urbano brasileiro ${ }^{9}$ e em crianças índias do Alto Xingu ${ }^{10}$. Estudo recente, utilizando dose de lactose mais próxima da utilizada na alimentação habitual, mostrou menor frequiência de má absorção de lactose em um grupo de escolares do interior do Estado de São Paulo, com o emprego do teste do hidrogênio no ar expirado ${ }^{11}$. O conhecimento da prevalência da deficiência ontogenética de lactase e da intolerância à lactose constitui um dos subsídios a serem considerados quando é necessário a elaboração de programas de intervenção nutricional.

Por outro lado, como reflexo de condições ambientais e de saneamento básico inadequados, pode estar presente um componente da enteropatia ambiental, que acarreta anormalidades funcionais e morfológicas do intestino delgado $^{12,13}$. Nesta circunstância, pode haver anormalidades na digestão e assimiliação dos nutrientes. Freqüentemente, a enteropatia ambiental se associa com proliferação excessiva de bactérias no intestino delgado proximal, que pode ser pesquisada com o emprego de um método não-invasivo, ou seja, o teste do hidrogênio no ar expirado após ingestão de lactulose por via oral ${ }^{14}$.

Levando-se em consideração a importância das diversas variáveis acima expostas, este estudo teve por objetivo avaliar o estado nutricional, a absorção e a tolerância à lactose e a ocorrência de sobrecrescimento bacteriano no intestino delgado em crianças indígenas terenas, moradoras em duas aldeias localizadas no Município de Aquidauana no Estado do Mato Grosso do Sul.

\section{Casuística e métodos}

\section{Os índios terenas}

$\mathrm{O}$ estudo foi realizado nas aldeias terenas de Limão Verde e Córrego Seco, situadas no Município de Aquidauana, no Estado do Mato Grosso do Sul. A estimativa da população total destas aldeias no início do trabalho de campo, em 1995, era de 1.500 habitantes. O contato destes índios, pertencentes ao grupo lingüístico Aruak com nossa sociedade, foi registrado a partir de meados do século XIX, sendo que os mesmos participaram da Guerra do Paraguai. Suas terras foram demarcadas no início do século XX. Desde essa época, já ocorriam conflitos quanto às terras pertencentes a estes grupos indígenas. Nas aldeias, as edificações de uso da comunidade (sede administrativa, ambulatório, escola) são construídas em alvenaria e possuem luz elétrica, fornecida pela rede pública, e água encanada a partir de um poço artesiano. As habitações propriamente ditas são construídas com paredes de troncos de árvore e barro, sendo a cobertura com folhas de buriti. Não dispõem de eletricidade e água encanada. Os índios terenas cultivam milho, feijão, arroz, mandioca e frutas, sendo a quantidade excedente à subsistência comercializada no mercado da cidade de Aquidauana.

\section{Casuística}

O presente estudo é do tipo transversal, analisando a população infantil moradora nas aldeias já mencionadas. Durante a primeira etapa do estudo, no ano de 1995, como critério único de inclusão na casuística, pretendeu-se estudar o maior número possível de crianças com idade inferior a 10 anos. Foi possível incluir a totalidade da população desta faixa etária, 264 crianças (125 do sexo masculino e 139 do sexo feminino). Todas realizaram avaliação do peso e estatura. Posteriormente, de acordo com a disponibilidade de condições operacionais para realizar o trabalho de campo, foram realizados: 244 (92,4\%) exames parasitológicos de fezes, $251(92,4 \%)$ testes de tolerância e absorção da lactose, com base no hidrogênio no ar expirado, e 252 $(95,1 \%)$ testes respiratórios após ingestão de lactulose para a pesquisa de sobrecrescimento bacteriano no intestino delgado proximal. Menos de $10 \%$ da população alvo, que realizou a avaliação antropométrica, deixou de realizar o exame parasitológico de fezes ou os testes do hidrogênio no ar expirado com lactose ou lactulose. Este fato ocorreu por questões operacionais, uma vez que não se estabeleceu qualquer critério de exclusão. Caso a criança apresentasse episódio de diarréia aguda, uso de antimicrobiano ou outra doença infecciosa que pudesse interferir no teste respiratório, o exame era realizado pelo menos um mês após a recuperação da criança. $\mathrm{O}$ trabalho de campo se estendeu até março de 1997. Na ocasião da realização dos testes respiratórios, a mediana da idade (percentis 25 e 75 entre parenteses) das crianças foram 6 anos e 8 meses ( 4 anos e 6 meses; 9 anos e 6 meses) para a lactose $(n=251)$, e 6 anos e 8 meses ( 4 anos e 4 meses e 9 anos e 1 mês) para a lactulose $(n=252)$.

\section{Métodos}

\section{Avaliação antropométrica}

As medidas de peso e estatura foram obtidas de acordo com as recomendações de Jelliffe $(1968)^{1}$ para estudos na 
comunidade. Para a obtenção do peso, foram utilizadas duas balanças mecânicas da marca Filizola, uma para lactentes e outra para crianças maiores. As crianças foram pesadas despidas. A estatura foi mensurada até a idade de 2 anos, com a criança deitada e, na posição em pé, a partir desta idade. Para tanto, foram utilizados dois antropômetros. Para as crianças mensuradas em pé, tomou-se as devidas precauções para que a coluna e as pernas permanecessem retificadas. Os escores $\mathrm{Z}$ e as percentagens de adequação do peso para a idade, peso para a estatura e estatura para a idade foram calculados pelo programa EPIInfo versão $6.2^{15}$, com base nos valores de referência da tabela do NCHS - National Center for Health Statistics ${ }^{16}$. Como limite de corte para caracterização de desnutrição, de acordo com os escores Z, foi adotado o valor de $-2,0$ desvios-padrão, conforme recomendado pela Organização Mundial de Saúde ${ }^{17}$.

$\mathrm{O}$ estado nutricional das crianças com idade inferior a 60 meses foi avaliado, também, pelo critério de Gomez, que se baseia na adequação percentual do peso para a idade ${ }^{18}$. A data de nascimento foi obtida na certidão de nascimento de cada criança índia.

\section{Testes do hidrogênio no ar expirado}

Os testes do hidrogênio no ar expirado, com lactose e lactulose, foram realizados pela manhã, com as crianças em jejum pelo período de 8 a 12 horas. Para as crianças em aleitamento natural $(n=29)$, foi exigido o período mínimo de jejum de 4 horas.

\section{Sobrecarga com lactose}

Cada criança recebeu a dose única de 18 gramas de lactose em solução aquosa a $10 \%$. Foram coletadas amostras de ar expirado, para a determinação da concentração de hidrogênio, imediatamente antes (amostra basal ou em jejum) e aos 30, 60, 90 e 120 minutos após a administração da lactose ${ }^{11}$. A interpretação do teste baseou-se nas recomendações da literatura ${ }^{14,19}$, considerando o incremento da concentração de hidrogênio no ar expirado, em qualquer uma das amostras, em relação ao valor basal: absorção adequada de lactose - incremento inferior a $10 \mathrm{ppm}$ (partes por milhão); suspeita de deficiência de lactase - incremento entre 10 e 20 ppm; e deficiência de lactase - incremento superior a $20 \mathrm{ppm}$. Intolerância à lactose foi caracterizada quando, nos 3 dias subseqüentes à ingestão das 18 gramas de lactose, a criança apresentasse um ou mais dos seguintes sintomas: flatulência, dor abdominal e diarréia. Estes sintomas foram aferidos nesse período, por um dos pesquisadores, com o auxílio de monitores de saúde da própria comunidade.

\section{Sobrecarga com lactulose}

No teste respiratório com lactulose, para a pesquisa de proliferação excessiva de bactérias no intestino delgado proximal, ou seja, sobrecrescimento bacteriano, foi admi- nistrado 5 gramas de lactulose, em solução aquosa a 50\%, após a coleta de ar expirado em jejum. Foram coletadas novas amostras de ar expirado aos 20, 40, 60, 90 e 120 minutos, após a administração de lactulose. Proliferação excessiva de bactérias no intestino delgado proximal foi caracterizada quando ocorreu pico transitório de hidrogênio, com elevação mínima de 10 ppm em relação ao basal, nas amostras coletadas aos 20, 40 ou 60 minutos. Com base neste teste, as crianças foram classificadas, também, em produtoras e não produtoras de hidrogênio se apresentassem, respectivamente, aumento na concentração de hidrogênio maior/igual ou menor do que 10 ppm em relação ao valor basal, em qualquer uma das cinco amostras coletadas após a ingestão de lactulose ${ }^{14}$.

As amostras de ar expirado foram coletadas com o auxílio de uma máscara da marca $\mathrm{Ambu}^{\circledR}$, com válvula de uma única via, à qual estava conectada uma seringa de 60 $\mathrm{ml}$, por meio de uma torneira de 3 vias. A concentração de hidrogênio foi mensurada por cromatografia de gás (aparelho Quintron, modelo CM2). O aparelho foi calibrado antes e durante as análises, utilizando como padrão uma mistura contendo 100 ppm de hidrogênio com ar sintético.

\section{Exame parasitológico de fezes}

As amostras de fezes foram coletadas e homogeneizadas em frascos de plástico, contendo solução conservante de mertiolate-iodo-formol. No exame parasitológico de fezes, foram utilizadas as técnicas de concentração de Faust e Hoffmann ${ }^{20}$.

$\mathrm{Na}$ análise estatística, foi utilizado o teste de KruskalWallis para comparar os escores $Z$ dos dados antropométricos, segundo três faixas etárias $(0$ a 11,12 a 59 e 60 a 120 meses), sendo complementado pelo teste de comparações múltiplas de Dunn, quando se observou diferença estatisticamente significante. O teste do qui-quadrado foi utilizado para avaliar a existência de associação entre variáveis qualitativas. Os cálculos foram realizados com o emprego do programa SigmaStat.

$\mathrm{O}$ projeto de pesquisa foi analisado e oficialmente aprovado pela Fundação Nacional do Índio, tendo sido obtido o consentimento verbal após esclarecimento por ocasião da realização do trabalho de campo. A Comissão de Ética da Universidade Federal de São Paulo - Escola Paulista de Medicina também analisou e aprovou o projeto do presente estudo.

\section{Resultados}

No momento da avaliação, as crianças estudadas não apresentavam sintomatologia vinculada ao trato gastrintestinal pelo período mínimo de 30 dias. A avaliação inicial dos resultados mostrou que não havia diferença nas variáveis estudadas segundo o sexo.

$\mathrm{Na}$ Tabela 1 são apresentados os escores $\mathrm{Z}$ de peso para idade, peso para estatura e estatura para idade, de acordo com as seguintes faixas de idade: menores de 12 meses, 
Tabela 1 - Escores Z (mediana e percentis 25 e 75 entre parênteses) do peso para a idade, peso para a estatura e estatura para a idade das crianças índias terenas segundo o grupo etário

\begin{tabular}{lcccc}
\hline & $\mathbf{0} \mid-\mathbf{1 2} \mathbf{~ m}$ & $\mathbf{1 2}-\mathbf{6 0} \mathbf{~ m}$ & $\mathbf{6 0} \mid-\mathbf{1 2 0} \mathbf{~ m}$ \\
$(\mathbf{n}=\mathbf{3 4})$ & $-0,66$ & $-0,50$ & $\mathbf{p}^{\dagger}$ \\
\hline Peso-Idade & $(-1,19+0,63)$ & $(-1,27+0,13)$ & $-0,09$ & $0,004^{*}$ \\
Peso-Estatura & $+0,60$ & $+0,28$ & $+0,73-0,45)$ & \\
& $(-0,42-1,40)$ & $(-0,56-0,92)$ & $(-0,12-1,25)$ & 0,096 \\
Estatura-Idade & $-0,85$ & $-1,17$ & $-0,60$ & $<0,001^{*}$ \\
& $(-1,21-0,55)$ & $(-2,05-0,56)$ & $(-1,22-0,23)$ & \\
\hline
\end{tabular}

\section{Teste de comparações múltiplas de Dunn}

\section{Peso-Idade}

$$
\begin{gathered}
0|-12 \times 12|-60: p>0,05 \\
12|-60 \times 60|-120: p<0,05^{*} \\
0|-12 \times 60|-120: p>0,05
\end{gathered}
$$

\section{Estatura-Idade}

$$
\begin{gathered}
0|-12 \times 12|-60: p>0,05 \\
12|-60 \times 60|-120: p<0,05^{*} \\
0|-12 \times 60|-120: p>0,05
\end{gathered}
$$

† Teste de Kruskal-Wallis * estatisticamente significativo

entre 12 e 60 meses e entre 60 e 120 meses. As medianas de peso para a idade e de estatura para a idade foram negativas, indicando que o grupo avaliado apresenta valores inferiores aos esperados pela tabela do NCHS. Observa-se, ainda, que a mediana de peso para a estatura é positiva, ou seja, em relação à tabela de referência, o grupo avaliado apresenta maior peso para um determinado valor de estatura. Nas comparações entre as três faixas etárias consideradas, observou-se diferença estatística do peso para idade que foi menor nas crianças entre 12 e 60 meses, em relação às crianças com idade entre 60 e 120 meses. Constatou-se, ainda, que o déficit de estatura para a idade foi maior nas crianças entre 12 e 60 meses do que naquelas entre 60 e 120 meses. Vale mencionar que não foram observadas diferenças estatísticas na comparação dos escores Z entre os sexos (resultados não apresentados).
A Tabela 2 mostra o número de crianças consideradas portadoras de desnutrição por apresentarem escore $\mathrm{Z}$ menor do que -2,0 desvios-padrão. Observa-se maior proporção de crianças com déficit de peso para a idade e estatura para a idade na faixa etária entre 12 e 60 meses.

Na Tabela 3, é apresentado o estado nutricional das crianças com idade inferior a 60 meses, de acordo com o critério de Gomez.

Na Tabela 4, é apresentada a capacidade de absorção de lactose, avaliada pelo teste do hidrogênio no ar expirado, das crianças índias terenas, de acordo com a idade inferior ou maior/igual a 4 anos. Suspeita de absorção deficiente de lactose e absorção deficiente de lactose ocorreu em 54,8\% e $34,5 \%$, respectivamente, das 197 crianças com idade maior ou igual a 4 anos. Intolerância à lactose ocorreu em

Tabela 2 - Número e percentagens de crianças índias terenas com déficit do peso para a idade, peso para a estatura, e estatura para a idade segundo os escores $Z(<-2,0$ desvios-padrão) e o grupo etário

\begin{tabular}{lccccc}
\hline & $\begin{array}{c}\mathbf{0}-\mathbf{1 2} \\
(\mathbf{n = 3 4})\end{array}$ & $\begin{array}{c}\mathbf{1 2}+\mathbf{6 0} \\
(\mathbf{n = 1 1 1})\end{array}$ & $\begin{array}{c}\mathbf{6 0}-\mathbf{6 2 0} \\
(\mathbf{n = 1 1 9})\end{array}$ & $\begin{array}{c}\text { Total } \\
(\mathbf{n = 2 6 4 )}\end{array}$ & $\mathbf{p}$ \\
\hline Peso-Idade & $0(0,0 \%)$ & $8(7,2 \%)$ & $1(0,8 \%)$ & $9(3,4 \%)$ & $0,015^{*}$ \\
Peso-Estatura & $1(2,9 \%)$ & $1(0,9 \%)$ & $2(1,7 \%)$ & $4(1,5 \%)$ & 0,682 \\
Estatura-Idade & $1(2,9 \%)$ & $29(26,1 \%)$ & $7(5,9 \%)$ & $37(14,0 \%)$ & $0,000^{*}$ \\
\hline
\end{tabular}

Partição do qui-quadrado:

$\begin{array}{ll}\text { Peso-Idade: } & 60|-120>0|-12 \text { e } 60 \mid-120 \\ \text { Estatura-Idade: } & 60|-120>0|-12 \text { e } 60 \mid-120\end{array}$

* estatisticamente significativo 
Tabela 3 - Estado nutricional das crianças índias terenas de acordo com o critério de Gomez

\begin{tabular}{lccc}
\hline & $\mathbf{0} \mid \mathbf{1 2} \mathbf{~ m}$ & $\mathbf{1 2} \mid \mathbf{- 6 0} \mathbf{~ m}$ & Total \\
\hline Sem DEP* & $19(55,9 \%)$ & $68(61,3 \%)$ & $87(60 \%)$ \\
DEP I & $14(41,2 \%)$ & $40(36,0 \%)$ & $54(37,2 \%)$ \\
DEP II & $1(2,9 \%)$ & $3(2,7 \%)$ & $4(2,8 \%)$ \\
DEP III & $0(0,0 \%)$ & $0(0,0 \%)$ & $0(0,0 \%)$ \\
\hline Total & 34 & 111 & 145 \\
\hline
\end{tabular}

* DEP = desnutrição energético-protéica

Não analisável estatisticamente

$73(37,1 \%)$ das 197 crianças com idade maior ou igual a 4 anos. Na Tabela 5, é relacionada a capacidade de absorção da lactose com a ocorrência de intolerância à lactose. Intolerância à lactose ocorreu em $9(8,3 \%)$ das 108 crianças com suspeita de absorção deficiente de lactose, e em 64 $(94,1 \%)$ das 68 crianças com má absorção de lactose. Com base nos dados da Tabela 5, observa-se que nas crianças com suspeita de absorção deficiente ( $\mathrm{n}=108)$ e com absorção deficiente $(\mathrm{n}=68)$ de lactose (todas com idade maior do que 4 anos, conforme mostra a Tabela 4), a proporção de intolerânciaé estatisticamente superior $\left(\chi^{2}=122,9 ; \mathrm{p}<0,001\right)$ entre as crianças com absorção deficiente $(64 / 68 ; 94,1 \%)$ do que nas crianças com suspeita de absorção deficiente (9/108; 8,3\%).

O teste do hidrogênio no ar expirado após a administração de lactulose demonstrou que 29 (11,5\%) de 252 crianças apresentavam sobrecrescimento bacteriano no intestino delgado proximal, ou seja, elevação de mais de 10 ppm na concentração de hidrogênio no ar expirado em relação à amostra basal de jejum. A ocorrência de sobrecrescimento bacteriano nas crianças com idade inferior a 4 anos foi igual a 8,6\% (5/58), e nas crianças com idade maior ou igual a 4 anos igual a $12,4 \%$ (24/194), sendo que esta diferença não

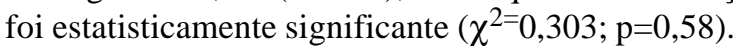

Tabela 4 - Absorção intestinal de lactose de acordo com o teste do hidrogênio no ar expirado em crianças índias terenas segundo a idade

\begin{tabular}{lccc}
\hline & \multicolumn{2}{c}{ Grupo etário } & \\
& $\begin{array}{l}<\mathbf{4} \text { anos } \\
(\mathbf{n = 5 4})\end{array}$ & $\begin{array}{c}\geq \mathbf{4} \text { anos } \\
(\mathbf{n = 1 9 7})\end{array}$ & Total \\
\hline Boa absorção & $54(100,0 \%)$ & $21(10,7 \%)$ & $75(29,9 \%)$ \\
$\begin{array}{l}\text { Suspeita de } \\
\text { absorção deficiente }\end{array}$ & $0(0,0 \%)$ & $108(54,8 \%)$ & $108(43,0 \%)$ \\
$\begin{array}{l}\text { Absorção } \\
\text { deficiente }\end{array}$ & $0(0,0 \%)$ & $68(34,5 \%)$ & $68(27,1 \%)$ \\
\hline
\end{tabular}

Os parasitas intestinais identificados com maior freqüência nos exames parasitológicos de fezes das 244 crianças foram: Giardia lamblia em 74 (30,3\%) crianças, Hymenolepsis nana em 26 (10,6\%), Necator americanus em 10 (3,3\%), Strongyloides stercoralis em 8 (3,3\%), Ascaris lumbricoides em $4(1,6 \%)$ e Taenia sp em $1(0,4 \%)$ criança.

Tabela 5 - Intolerância à lactose relacionada com a capacidade de absorção intestinal de lactose, aferida com o teste do hidrogênio no ar expirado, em crianças índias terenas

\begin{tabular}{lccc}
\hline & $\begin{array}{c}\text { Tolerância } \\
(\mathbf{n = 1 7 8})\end{array}$ & $\begin{array}{c}\text { Intolerância } \\
(\mathbf{n}=\mathbf{7 3})\end{array}$ & $\begin{array}{c}\text { Total } \\
(\mathbf{n = 2 5 1})\end{array}$ \\
\hline Boa absorção & $75(42,1 \%)$ & $0(0,0 \%)$ & $75(29,9 \%)$ \\
$\begin{array}{l}\text { Suspeita de } \\
\text { absorção deficiente }\end{array}$ & $99(55,6 \%)$ & $9(12,3 \%)$ & $108(43,0 \%)$ \\
\begin{tabular}{l} 
Absorção deficiente \\
\hline
\end{tabular} & $4(2,3 \%)$ & $64(87,7 \%)$ & $68(27,1 \%)$ \\
\hline
\end{tabular}

\section{Discussão}

Desde a descrição dos escores $\mathrm{Z}$ e a escolha da tabela americana do NCHS - National Center for Health Statistics como referência internacional em $1977^{21}$, a Organização Mundial da Saúde vem reafirmando esta escolha ${ }^{16,17}$ e recomenda que se utilize o limite de corte de $-2,0$ desviospadrão, abaixo do qual se caracteriza déficits de peso para a idade, peso para a estatura e estatura para idade.

Na Tabela 1, observa-se que as medianas dos escores Z de peso-idade e estatura-idade, por serem negativas, indicam que a distribuição destas variáveis estão desviadas para a esquerda da referência e que o peso para a estatura apresenta desvio para a direita. A proporção global de déficit ( $<-2,0$ desvios-padrão) de peso-idade foi igual a $3,4 \%$, peso-estatura igual a $1,5 \%$ e estatura-idade $14,9 \%$. No contexto dos índios brasileiros, estes dados são semelhantes aos obtidos em 1992, em crianças índias da mesma faixa etária, no Alto Xingu ${ }^{5}$, onde déficit de estatura para idade foi caracterizado em 19,8\% das crianças, e em nenhuma criança se constatou déficit de peso para a estatura. No que se refere ao Alto Xingu, na década de 1970, se verificou que era baixa a prevalência de desnutrição aguda ${ }^{3,4}$, segundo os critérios antropométricos independentes da idade que precisaram ser utilizados, uma vez que a idade exata não era conhecida naquele época. Deve ser mencionado que em outros grupos de índios brasileiros ${ }^{6,7}$, da América Latina ${ }^{22}$ e da América do Norte $^{23}$, em relação à tabela do NCHS 
adotada como referência internacional, apresentam o mesmo padrão antropométrico de maior prevalência de déficit de estatura para a idade do que do peso para a estatura. A prevalência de desnutrição, de acordo com o critério de Gomez, nos menores de 5 anos, foi igual a $40,0 \%$, sendo $37,2 \%$ incluídos no primeiro grau de desnutrição. O critério de Gomez foi utilizado pelo desejo de comparar os resultados do presente estudo com aqueles obtidos previamente, em nosso país, independentemente da presença ou não de déficit na relação estatura-idade ${ }^{24}$. Assim, dentro do contexto do Brasil, a prevalência de desnutrição nas crianças terenas, pelo mesmo critério diagnóstico de Gomez, foi semelhante ao observado em crianças da mesma faixa etária, habitantes na região rural do Brasil, que apresentam características de vida semelhantes às observadas nas aldeias terenas estudada ${ }^{24}$.

Os fatores ambientais podem influenciar na plena expressão do potencial genético para o crescimento. Neste sentido, a enteropatia ambiental pode ser um fator agravante para o crescimento de crianças que vivem em meio ambiente com más condições de saneamento. Ou seja, a enteropatia ambiental potencialmente pode impedir o completo aproveitamento da dieta que, muitas vezes, nessas comunidades, não é adequada do ponto de vista quantitativo e qualitativo. A pesquisa de sobrecrescimento bacteriano no intestino delgado por meio do teste do hidrogênio no ar expirado, após ingestão de 10 gramas de lactulose, foi realizada em um estudo recentemente realizado no interior do Estado de São Paulo ${ }^{11}$. Foram estudadas crianças da zona rural, zona urbana e moradoras em favela. $\mathrm{O}$ teste respiratório com lactulose foi positivo em $6(30,0 \%)$ das 20 crianças moradoras na favela e em nenhuma das 63 crianças que não moravam em favela, sendo essa diferença estatisticamente significante. Entre as crianças terenas, sobrecrescimento bacteriano no intestino delgado, segundo o teste respiratório após ingestão de 5 gramas de lactulose, ocorreu em $11,5 \%$ das 252 crianças avaliadas. A dose única de 5,0 gramas de lactulose foi escolhida para facilitar a realização do trabalho de campo e, ainda, para reduzir o possível risco de efeitos colaterais durante este teste, que poderiam comprometer a finalização do trabalho de campo, que foi realizado em uma comunidade fechada. Teoricamente, por ter sido empregada dose de 5 gramas de lactulose, estes dados podem estar subestimados na comparação com os valores obtidos no estudo de Reis et al. ${ }^{11}$ Este resultado pode ser considerado como um indício da ocorrência de enteropatia ambiental assintomática nas crianças índias terenas, refletindo as condições desfavoráveis do seu meio ambiente. Outro aspecto que indica condições ambientais desfavoráveis é a alta prevalência de giardíase assintomática, presente em $30,3 \%$ das crianças avaliadas, sendo interessante mencionar que a ascaridíase e a tricocefalíase não são freqüentes nesta comunidade.

No Brasil, a enteropatia ambiental (tropical) sintomática foi descrita pela primeira vez em 1980 , em crianças com diarréia crônica com idade inferior a 4 anos. Uma das anormalidades funcionais descritas foi a má absorção secundária de lactose, presente em metade dos pacientes ${ }^{12,25}$.

Por outro lado, existem informações de que no Brasil, a exemplo de outros países do mundo, é comum a deficiência ontogenética de lactase, responsável por má absorção primária de lactose em crianças com mais de 4 anos de idade, adolescentes e adultos ${ }^{8-11}$. Nas crianças índias terenas, observou-se que a ocorrência de sobrecrescimento bacteriano no intestino delgado nas crianças com idade inferior a 4 anos $(8,6 \%)$, faixa etária na qual não se caracterizou má absorção de lactose, não foi diferente de acordo com a análise estatística em relação à frequiência de sobrecrescimento bacteriano nos maiores de 4 anos $(12,4 \%)$. É importante mencionar que a partir de 4 anos de idade observouse déficit ou má absorção de lactose em $89,3 \%$ das crianças terenas. Intolerância à lactose ocorreu em maior proporção entre as crianças com mais de 4 anos de idade e má absorção de lactose $(94,1 \%)$ do que entre aquelas com suspeita de absorção deficiente $(8,3 \%)$, sendo a diferença estatisticamente significante. Estes dados são compatíveis com estudos prévios realizados em nosso meio, com base na curva glicêmica ${ }^{8-10}$.É interessante comentar que o teste do hidrogênio no ar expirado é considerado o método indireto com maior precisão na avaliação da absorção da lactose. O único artigo publicado no Brasil que utilizou esta técnica, em escolares com idade entre 7 e 15 anos, foi realizado no interior do estado de São Paulo, inclusive com a mesma dose fixa de 18 gramas de lactose, tendo demonstrado prevalência bem inferior de má absorção $(22,9 \%)$ e intolerância $(12,0 \%)$ à lactose ${ }^{11}$. Vale lembrar que a dose de $2 \mathrm{~g} / \mathrm{kg}$ de lactose, até o máximo de 50 gramas, utilizada em estudos realizados previamente no $\mathrm{Brasil}^{8-10}$, reflete a capacidade intestinal de absorção de lactose. No entanto, por se tratar de uma sobrecarga, não reflete com precisão a possibilidade de intolerância ao consumo habitual de leite que, teoricamente, pode ser melhor avaliado com dose mais próxima da fisiológica, semelhante à utilizada no presente estudo e naquele realizado no interior do estado de São Paulo ${ }^{11}$. Quanto ao trabalho de campo, deve ser mencionado que a escolha de dose fixa de lactose e lactulose foi fundamental no sentido dispensar as mensurações individuais da quantidade de carboidrato e água para o preparado das soluções utilizadas nos testes respiratórios do hidrogênio no ar expirado.

Em conclusão, as crianças índias terenas não apresentam desnutrição atual, no entanto, apresentam desvio para a esquerda da distribuição de estatura para a idade em relação à tabela do NCHS, de forma similar a outros grupos indígenas da América Latina e do Norte. A prevalência de deficiência ontogenética de lactase nas crianças indígenas terenas é elevada, a exemplo de outros grupos populacionais do nosso país. Uma parcela das crianças apresenta evidência de enteropatia ambiental assintomática, que pode ser um indicativo da necessidade de melhorar as condições ambientais em que vive esta comunidade. 


\section{Referências bibliográficas}

1. Jelliffe DB. Evaluación del estado nutricional de la comunidad. Ginebra: Organización Mundial de la Salud; 1968.p.201.

2. Black FL, Hierholzer WJ, Black DP, Lamm SH, Lucas L. Nutritional status of Brazilian Kayapo Indians. Hum Biol 1977;49:139-53.

3. Fagundes-Neto U, Baruzzi RG, Wehba J, Silvestrini WS, Morais MB, Cainelli M. Observations of the Alto Xingu Indians (Central Brazil) with special reference to nutritional evaluation in children. Am J Clin Nutr 1981;34:2229-35.

4. Morais MB, Fagundes-Neto U, Baruzzi RG, Prado MC, Wehba J, Silvestrini WS. Estado nutricional de crianças índias do Alto Xingu e avaliação do uso do perímetro braquial no diagnóstico da desnutrição protéico-calórica. Rev Paul Med 1990;8:245-51.

5. Mattos AP, Morais MB, Rodrigues AD, Baruzzi RG. Nutritional status and dietary habits of Indian children from Alto Xingu (Central Brazil) according to age. J Am Coll Nutr 1999;18:88-94.

6. Santos RV, Coimbra CEA. Socioeconomic transition and physical growth of Tupi-Mondê Amerindian children of the Aripuanã Park, Brazilian Amazon. Human Biol 1991;63:795-819.

7. Gugelmin SA, Santos RV, Leite MS. Crescimento físico de crianças indígenas xavantes de 5 a 10 anos de idade em Mato Grosso. J Pediatr (Rio J) 2001;77:17-22.

8. Nobrega FJ, Yin L. Estudo de absorção e tolerância à lactose em população adulta de bom nível socioeconômico, realizado na cidade de São Paulo. Rev Bras Clin Ter 1984;13:327-30.

9. Silvestrini WS. Avaliação da tolerância e absorção de lactose em escolares do primeiro grau do Município de São Paulo [tese]. São Paulo: Escola Paulista de Medicina; 1983.

10. Wehba J. Avaliação da capacidade de absorção da lactose. Estudo em população do Alto Xingu [tese]. São Paulo: Escola Paulista de Medicina; 1976.

11. Reis JC, Morais MB, Fagundes-Neto U. Teste do H2 no ar expirado na avaliaçäo de absorção de lactose e sobrecrescimento bacteriano no intestino delgado de escolares. Arq Gastroenterol 1999;36:169-76.

12. Fagundes-Neto U, Viaro T, Wehba J, Patricio FR, Machado NL. Tropical enteropathy (environmental enteropathy) in early childhood: a syndrome caused by contaminated environment. J Trop Pediatr 1984;30:204-9.

13. Morais MB, Fagundes-Neto U, Machado NL. Enteropatia ambiental em crianças moradoras na periferia da cidade de São Paulo - capacidade de absorção da D-xilose. J Pediatr (Rio J) 1984;57:32-6.
14. Davidson GP, Butler RN. Breath analysis. In: Walker WA, Durie PD, Hamilton JR, Walker-Smith J, Watkins JB, eds. Pediatric gastrointestinal disease. 3rd edn. Ontario: BC Decker; 2000. p.1529-37.

15. Dean AG. Epi-Info version 5.1: a word processor, database and statistics program for epidemiology on micro-computers. Georgia, Center for Disease Control; 1990.

16. World Health Organization. Measuring change in nutritional status: guidelines for assessing the nutritional impact of supplementary feeding programs for vulnerable groups. Geneva, World Health Organization; 1983. p.101.

17. World Health Organization Expert Committee. Physical status: the use and interpretation of anthropometry. WHO Technical Report Series, 854. Geneva: World Health Organization; 1995.

18. Gomez F. Desnutrición. Bol Méd Hosp Infant Mex 1946;3:543-51

19. Levitt MD. Production and excretion of hydrogen gas in man. $\mathrm{N}$ Engl J Med 1969; 281:122.

20. Pessoa SB. Parasitologia médica. $11^{\mathrm{a}}$ ed. Rio de Janeiro: Guanabara Koogan; 1982.

21. Waterlow JC, Buzina R, Keller W, Lane JM, Nichaman MZ, Tanner JM. The presentation and use of height and weight data for comparing the nutritional status of groups of children under the age of 10 years. Bull WHO 1977,55:489-98.

22. Hodge LG, Dufour DL. Cross-sectional growth of young Shipibo Indian children in eastern Peru. Am J Phys Anthropol 1991;84:35-41.

23. Stinson S. Physical growth of Ecuadorian Chachi Amerindians. Am J Hum Biol 1989;1:696-707.

24. INAN. Pesquisa Nacional sobre Saúde e Nutrição. Resultados preliminares. Brasília. INAN/IBGE/IPEA; 1990.

25. Fagundes-Neto U, Viaro T, Wehba J, Machado NL, Patrício FRS, Michalany J. Enteropatia tropical: alterações morfológicas e funcionais do intestino delgado e suas repercussões sobre o estado nutricional. Arq Gastroenterol 1981;18:177-82.

Endereço para correspondência:

Dra. Gildney Maria dos Santos Alves

Rua Dom Aquino, 1102

CEP 79002-180 - Campo Grande, MS 